\title{
Is it time to relax research on death rates of supercentenarians?
}

\section{Eric Le Bourg}

E. Le Bourg, Centre de Recherches sur la Cognition Animale (CRCA), Centre de Biologie Intégrative (CBI Toulouse), Université de Toulouse, CNRS, UPS, Toulouse, France

e-mail address: eric.le-bourg@univ-tlse3.fr

Orcid iD: https://orcid.org/0000-0001-5578-025X

Main text word count: 1648 
No abstract for Letters to the Editor

Key-words: Maximal lifespan — Humans — Mortality rates 


\section{Dear Editor,}

Statements that mean and maximal lifespan could increase to 150 years and more, and even without any limit, are not breaking news, as they have been claimed for decades and centuries. For instance, the French mathematician Condorcet [1] wrote in 1795 that, in the future, lifespan could continuously increase before reaching, or not, an asymptotic limit. Similarly, the French (formerly Russian) biologist Métalnikov [2] wrote in 1937 that people could live well beyond 150 years, provided living conditions would be optimal. Robine and Hermann [3] have reported such claims, including those that endorsed the idea that Patriarchs of the Bible lived for centuries. Nowadays, de Grey [4] has claimed that people born in 2000 could live for 5,000 years, well above the assumed lifespan of Patriarchs. The idea, not to say the hope, that lifespan coud increase without any clear limit, or so far a limit that it is difficult to envisage it, has given rise to many attempts to increase lifespan (for a review see [5]). Today, only some biogerontologists explicitly accept that lifespan could increase with no or a remote limit, as Guarante and Kenyon [6] who wrote that "we begin to think of ageing as a disease that can be cured". The idea that lifespan could increase at will is let to transhumanists (e.g., [7]) and to biotechnology companies thriving on the hope to defeat ageing [8].

However, there is a long-lasting debate among demographers and biogerontologists on mean and maximal lifespan increases in the future. The 1997 collective book Longevity: to the limits and beyond [9] confronted the points of view of scholars arguing either that there are practical limits to life expectancy in France [10] or that the average French baby could live to 100 [11]. In subsequent years, Oeppen and Vaupel [12] wrote that country "record life expectancy will reach 100 in about six decades" and Christensen et al. [13] that the median lifespan of the 2007 Japanese birth cohort could be 107 years, and thus probably longer for women. Recently, Vaupel et al. [14] wrote that "if the current pace of progress in life expectancy continues, most children born this millenium will celebrate their $100^{\text {th }}$ birthday", which should probably be understood as "the beginning of the millenium" 
because, obviously, forecasting what would occur in several centuries from now has not any heuristic value.

Beside forecasts of life expectancy, one can wonder what is the maximal lifespan, i.e., the lifespan of the last survivor (Maximal Reported Age at Death, MRAD), and if the lifespan of the record-woman Jeanne Calment, 122 years and 164 days, will remain the MRAD. Estimating MRAD requires to know mortality rates at extreme ages. It has been proposed that these rates fit to the wellknown Gompertz trajectory, i.e., they increase with age (e.g., [15]), or that a plateau is observed above 100 or 105 years of age, with a yearly 50\% mortality rate (e.g., [16]). In the first case, MRAD is reached when the death rate is $100 \%$, the last survivor dying in this last time-interval. However, depending on the position and steepness of the slope, which could differ among populations or periods, this limit can be reached at various ages: the inescapable conclusion is that a fixed limit, say 126 years and not a single day more, cannot be practically established even if it theoretically exists. In the second case, MRAD is depending on the size of the cohort: with a 50\% yearly death rate above 100 years of age [16] only one among one million centenarians is expected to live to 120 . In other words, there is no theoretical limit to lifespan and the MRAD can slightly increase with the size of the cohort (e.g., 122 years if the number of centenarians is 4 million). Obviously, if the yearly mortality rate at, say, 105 years, is $50 \%$, it follows that MRAD will be higher if mortality rates are constant than if they increase with age.

The issue is that it is difficult to accurately estimate death rates at extreme ages, because the number of subjects is so low that confidence intervals are very high, and hot debates can occur (e.g., [17]) without any firm conclusion. For instance, Gampe [16], studying US supercentenarians (people reaching 110 years of age), wrote that "uncertainty for the annual probabilities of death increases quickly, and is large after age 113, at which point the data are too sparse to allow for an accurate assessment", but nevertheless concluded that "the shape of the survival curve suggests an exponential model, implying a constant hazard". Yet, the Figure 3.2. in [16] could also suggest that death rates 
slightly increase with age from 110 to 115 years of age, before a decreasing is observed. Because the $95 \%$ confidence intervals are so high, covering nearly the $0-100 \%$ mortality range at 113 years of age and all the range above this age, one could conclude anything from these results. Similar conclusions could be reached for the European supercentenarians (Figure 3.3 in [16]).

However, MRAD estimates are not really different whether one relies on constant or increasing with age death rates. Robine and Hermann [3] showed, using the 2013-2070 French forecasts, that in coming decades MRAD would be around 115 years in both cases, the estimate being slightly lower with a Gompertz model. Similar results were observed for the whole planet, MRAD being around 120 years, with a 124 years extreme value. In other words, no matter the model, MRAD will be around 115-120 years in coming decades, which is similar to or slightly higher than current values. These results also show that increasing the sample size from 65 million to 7.5 billion inhabitants only increases MRAD by no more than 5 years.

Ten years ago, I wrote in a review [18] of the book Supercentenarians [19] that "one may regret that this book on supercentenarians did not go beyond the beginning of this debate on maximal longevity". Today, this work has been done, even if the law governing death rates at extreme ages remains intractable, and nearly no authors conclude that maximal longevity will reach 150, 200 or higher values, even if the number of centenarians strongly increases in coming decades. In such conditions, and because it is possible to answer the final question of Vaupel [17], "how long can we live?", by saying that the observed maximal lifespan is 122 years, and maybe slightly longer in next decades [3], one may argue that time is ripe to relax efforts in searching the best model predicting MRAD, because both models provide the same answer: MRAD is ca 120 years. One can also argue that knowing whether MRAD will be 120,125 , or even 130 years in next decades has no practical importance, because only a very few persons will approach these ages. Thus, there is no concern about the "costs" of these very few supercentenarians. From a theoretical point of view, there is also no actual importance of knowing the best death rate model at the highest ages. As the number of last 
survivors is obviously very low, estimating mortality rates at these ages will always face the same problems as today: a too low number of subjects. There are other biological traits that appear to have a limit, even if it is not precisely known. Body size has increased in the last decades up to a plateau [20], and a very few people reach extreme heights, the world record being $2.72 \mathrm{~m}$ [21] but, as far as I know, there is no passionate debate to know whether there is a limit to human size. Maybe because the valuable question is modulating the growth of children, by increasing or decreasing it, and not to know whether, one day, a new height record will be established.

Therefore, thanks to the work of demographers and biogerontologists, we know how modelling mortality rates at very old ages — two models equally fit — and it is maybe not essential to spend the next ten years in trying to separate these two models. By contrast, knowing whether, before these extreme ages, mortality rates are increasing with age or are constant is useful. Gavrilov et al. [22] reported that the death rates of US centenarians have not decreased since the 1940 s, in contrast to what is observed for octogenarians and nonagenarians. Does it imply that the death rates of centenarians cannot decrease or is it a transient phenomenon, like was the stagnation of lifespan during the 1970s [23]? If death rates are actually constant in centenarians with a yearly $50 \%$ value, as hypothesised for supercentenarians [16], no medical progress is expected to occur at these ages. If they increase with age, one could hope to lower the curve of death rates, as done for younger ages, even if its slope cannot be modified. Similarly, selecting the best forecast model of life expectancy at birth in coming decades ([14] but see [24]), and thus knowing the number of old and very old people in each country, is of importance to better manage our societies in coming decades.

All these topics are of importance and need the attention of demographers and biogerontologists, but one can surely afford not to use our working time in coming years to separate the two models of mortality rates in supercentenarians, as they roughly provide the same MRAD. As a proverb stands, "It doesn't matter if a cat is black or white, as long as it catches mice": in supercentenarians, MRAD stands for the mice, and the Gompertz and the constant mortality models 
are the black and white cats.

\section{Acknowledgements}

Thanks are due to Jean-Marie Robine for his helpful comments on a previous draft of this article.

\section{References}

1 de Condorcet MJAN (de Caritat, marquis de Condorcet). Esquisse d'un tableau des progrès historiques de l'esprit humain (Outlines of an historical view of the progress of the human mind). Paris: Agasse; 1795. https://gallica.bnf.fr/ark:/12148/bpt6k281802

2 Métalnikov S. La lutte contre la mort. Paris: Gallimard; 1937.

3 Robine JM, Hermann FR. Maximal human lifespan. In: Rattan SIS, Barbagallo M, Le Bourg E, eds. Encyclopedia of biomedical gerontology, Vol. 2. London: Academic Press, 2020:385-399. doi: 10.1016/B978-0-12-801238-3.11456-4

4 de Grey ADNJ. Foreseeable and more distant rejuvenation therapies. In: Rattan SIS, ed. Aging interventions and therapies. Singapore: World Scientific Publishers, 2005:379-395. doi: 10.1142/9789812701329_0018

5 Stambler I. History of life-extensionism. In: Rattan SIS, Barbagallo M, Le Bourg E, eds. Encyclopedia of biomedical gerontology, Vol. 2. London: Academic Press, 2020:228-237. doi: 10.1016/B978-0-12-801238-3.11331-5

6 Guarente L, Kenyon C. Genetic pathways that regulate ageing in model organisms. Nature, 2000;408:255-262. doi: 10.1038/35041700

7 Kurzweil R, Grossman T. Bridges to life. In: Fahy GM, West MD, Coles LS, Harris SB, eds. The future of aging. Pathways to human life extension. Berlin: Springer, 2010:3-22. doi: 10.1007/978-90-481-3999-6_1

8 Brooker K. Google ventures and the search for immortality (March $9^{\text {th }}, 2015$ ) 
https://www.bloomberg.com/news/articles/2015-03-09/google-ventures-bill-maris- investing-inidea-of-living-to-500

9 Robine JM, Vaupel LW, Jeune B, Allard M, eds. Longevity: to the Limits and Beyond. Berlin: Springer, 1997. doi: 10.1007/978-3-642-60813_1

10 Olshansky SJ. Practical limits to life expectancy in France. In: Robine JM, Vaupel LW, Jeune B, Allard M, eds. Longevity: to the Limits and Beyond. Berlin: Springer, 1997:1-10. doi: 10.1007/978-3-642-60813_1

11 Vaupel JW. The average French baby may live 95 or 100 years. In: Robine JM, Vaupel LW, Jeune B, Allard M, eds. Longevity: to the Limits and Beyond. Berlin: Springer, 1997:11-27. doi: 10.1007/978-3-642-60813_2

12 Oeppen J, Vaupel JW. Broken limits to life expectancy. Science, 2002;296:1029-1031. doi: 10.1126/science. 1069675

13 Christensen K, Doblhammer G, Rau R, Vaupel JW. Ageing populations: the challenges ahead. Lancet, 2009;374:1196-1208. doi: 10.1016/S0140-6736(09)61460-4

14 Vaupel JW, Villavicencio F, Bergeron-Boucher MP. Demographic perspectives on the rise of longevity. Proc Natl Acad Sci USA, 2021;118:e2019536118. doi: 10.1073/pnas.2019536118

15 Gavrilov LA, Gavrilova NS. New trend in old-age mortality: gompertzialization of mortality trajectory. Gerontology, 2019;65:455-457. doi: 10.1159/000500141

16 Gampe J. Mortality of supercentenarians: estimates from the updated IDL. In: Maier H, Jeune B, Vaupel JW, eds. Exceptional lifespans. Berlin: Springer, 2021;29-35. doi: 10.1007/978-3-03049970-9_3

17 Vaupel JW. Preface. In: Maier H, Jeune B, Vaupel JW, eds. Exceptional lifespans. Berlin: Springer, 2021;1-8. doi: 10.1007/978-3-030-49970-9_1

18 Le Bourg E. Book review. Supercentenarians. Gerontology, 2011;57:480. doi: $10.1159 / 000320330$ 
19Maier H, Gampe J, Jeune B, Robine JM, Vaupel JW, eds. Supercentenarians. Dordrecht: Springer, 2010. doi: 10.1007/978-3-642-11520-2

20 Marck A, Antero J, Berthelot G, Saulière G, Jancovici JM, Masson-Delmotte V, Bœuf G, Spedding M, Le Bourg E, Toussaint JF. Are we reaching the limits of Homo sapiens ? Front Physiol, 2017;8:812. doi: 10.3389/fphys.2017.00812

21 de Herder WW. Acromegaly and gigantism in the medical literature. Case descriptions in the era before and the early years after the initial publication of Pierre Marie (1886). Pituitary, 2009;12:236-244. doi: 10.1007/s11102-008-0138-y

22 Gavrilov LA, Krut'ko VN, Gavrilova NS. The future of human longevity. Gerontology, 2017;63:524-526. doi: 10.1159/000477965

23 Gavrilov LA, Gavrilova NS, Nosov VN. Human life span stopped increasing: why? Gerontology, 1983;29:176-180. doi: 10.1159/000213111

24 Le Bourg E. New life expectancy forecasts are too optimistic. Biogerontology, 2021;22:655-658. doi: 10.1007/s10522-021-09942-x 